\title{
Induction of ROS-mediated cell death and activation of the JNK pathway by a sulfonamide derivative
}

\author{
REHAN AHMAD $^{1}$, MANSOOR-ALI VAALI-MOHAMMED $^{1}$, MOHAMMED ELWATIDY $^{2}$, \\ OMAR AL-OBEED ${ }^{1}$, KHAYAL AL-KHAYAL ${ }^{1}$, WAGDY M. ELDEHNA ${ }^{3}$, \\ HATEM A. ABDEL-AZIZ ${ }^{4}$, AHMED ALAFEEFY ${ }^{5}$ and MAHA ABDULLA ${ }^{1}$ \\ ${ }^{1}$ Colorectal Research Chair, Department of Surgery, King Khaled University Hospital, College of Medicine, \\ King Saud University; ${ }^{2}$ CMRC, College of Medicine, King Saud University, Riyadh 11472, Saudi Arabia; \\ ${ }^{3}$ Department of Pharmaceutical Chemistry, Faculty of Pharmacy, Kafrelsheikh University, Kafrelsheikh 33511; \\ ${ }^{4}$ Department of Applied Organic Chemistry, National Research Center, Cairo 12622, Egypt; \\ ${ }^{5}$ Department of Chemistry, Kulliyyah of Science, International Islamic University, Kuantan 25200, Malaysia
}

Received December 20, 2018; Accepted May 23, 2019

DOI: $10.3892 / \mathrm{ijmm} .2019 .4284$

\begin{abstract}
The emergence of colorectal cancer in developed nations can be attributed to dietary habits, smoking, a sedentary lifestyle and obesity. Several treatment regimens are available for primary and metastatic colorectal cancer; however, these treatment options have had limited impact on cure and disease-free survival, and novel agents need to be developed for treating colorectal cancer. Thus, the objective of this study was to explore the anticancer mechanism of a benzo $(1,3)$ dioxol-based derivative of sulfonamide. The compound's inhibitory effect on cell proliferation was determined using the MTT assay and the xCelligence RTDP machine. Alternations in the expression of Bcl-2 and inhibitor of apoptosis protein families were detected by western blotting. Apoptotic marker protein expression, including cytochrome $c$ and cleaved poly(ADP-ribose)polymerase was measured in the cytosolic extract of cells. Apoptosis and necrosis were detected by flow cytometry and immunofluorescence. Reactive oxygen species (ROS), and activation of caspase-3 and caspase-7 were measured using flow cytometry. Activation of the JNK pathway was detected by western blotting. We investigated
\end{abstract}

Correspondence to: Dr Rehan Ahmad, Colorectal Research Chair, Department of Surgery, King Khaled University Hospital, College of Medicine, King Saud University, P.O. Box 7805 (37), Riyadh 11472, Saudi Arabia

E-mail: arehan@ksu.edu.sa

Abbreviations: 3G, (4-((2-(benzo[d][1,3]dioxol-5-yl)quinazolin4-yl)amino)benzenesulfonamide); NAC, N-acetylcysteine; DMSO, dimethyl sulfoxide; ROS, reactive oxygen species; PI, propidium iodide

Key words: colorectal cancer, ROS, Bcl-2 family proteins, apoptosis, necrosis, JNK pathway the molecular mechanism of action of the sulfonamide derivative on colorectal cancer cells and found that the compound possesses a potent anticancer effect, which is primarily exerted by inducing apoptosis and necrosis. Interestingly, this compound exhibited little antiproliferative effect against the normal colonic epithelial cell line FHC. Furthermore, our results showed that the compound could significantly increase ROS production. Apoptosis induction could be attenuated by the free oxygen radical scavenger $\mathrm{N}$-acetyl cysteine (NAC), indicating that the antiproliferative effect of this compound on colorectal cancer cells is at least partially dependent on the redox balance. In addition, JNK signaling was activated by treatment with this derivative, which led to the induction of apoptosis. On the contrary, a JNK inhibitor could suppress the cell death induced by this compound. Our findings thus suggested a novel anticancer mechanism of a benzo $(1,3)$ dioxol-based derivative of sulfonamide for colorectal cancer cells and may have therapeutic potential for the treatment of colorectal cancer; however, further investigation is required.

\section{Introduction}

In 2018, colorectal cancer (CRC) accounted for 1.6 million cancer-associated mortalities worldwide (1). CRC is the third major cause of mortality due to cancer in both males and females in the United States of America (1). Furthermore, it is the most common cancer among men and the third most common among women in Saudi Arabia (2). A low incidence of CRC was reported until a few decades ago; however, recently, it has become widespread, accounting for $\sim 10 \%$ of cancer-associated mortalities in developed countries (3). Its emergence can be attributed to population aging, along with dietary habits and other risk factors, such as smoking, a sedentary lifestyle and obesity (3). Novel treatment options available for CRC include laparoscopic surgery, radiotherapy, and chemotherapies; however, the effectiveness of these treatment options on long-term disease-free survival is limited (3). Therefore, there is an urgent need to develop therapeutic treatments for CRC, specifically metastatic CRC. 
Oxidative stress plays an essential role in a number of physiological and pathological processes (4). A certain level of reactive oxygen species (ROS) is essential for normal cellular homeostasis (4). ROS accumulation can have a dual effect, which mainly depends on the concentration of ROS, the origin of the cancer and the activation of cellular signaling during tumorigenesis (4). A moderate level of ROS leads to cell damage, mutation and inflammation, resulting in tumor initiation and progression; however, excessive ROS accumulation in cancer cells leads to cell death via apoptosis, necrosis and autophagy (4). ROS levels are generally higher in cancer cells than in normal cells (4). Under these circumstances, cancer cells are more vulnerable to attack by excessive ROS from an exogenous source (5-7). Mitogen-activated protein kinases (Erk, p38, and JNK) serve a central role in ROS-mediated apoptotic signaling (8). Many studies have reported that ROS mediate cell death by regulating the JNK and p38 MAPK pathways (8-10).

In the present study, we assessed the molecular mechanism underlying the anticancer effects of the sulfonamide derivative (4-((2-(benzo[d][1,3]dioxol-5-yl)quinazolin-4-yl)amino) benzenesulfonamide), $3 \mathrm{G}$, on human CRC cell lines.

\section{Materials and methods}

Cell culture. HT-29 and SW620 cell lines were purchased from the American Type Culture Collection and maintained in Roswell Park Memorial Institute medium-1640 (RPMI-1640; Thermo Fisher Scientific, Inc.) containing $10 \%$ heat-inactivated fetal bovine serum (Invitrogen; Thermo Fisher Scientific, Inc.), $100 \mu \mathrm{g} / \mathrm{ml}$ streptomycin (Invitrogen; Thermo Fisher Scientific, Inc.), $100 \mathrm{U} / \mathrm{ml}$ penicillin (Invitrogen; Thermo Fisher Scientific, Waltham MA, USA), and $2 \mathrm{mmol} / \mathrm{l} \mathrm{L}$-glutamine (Invitrogen; Thermo Fisher Scientific, Inc.). FHC, normal colon epithelial cells (a gift from Dr Mohammad Azhar Aziz, KAIMRC), were grown in Dulbecco's modified Eagle's medium: F-12 (Invitrogen; Thermo Fisher Scientific, Inc.) with 10\% heat-inactivated fetal bovine serum (Invitrogen; Thermo Fisher Scientific, Inc.), $100 \mu \mathrm{g} / \mathrm{ml}$ streptomycin (Invitrogen; Thermo Fisher Scientific, Inc/), $100 \mathrm{U} / \mathrm{ml}$ penicillin (Invitrogen; Thermo Fisher Scientific, Inc.), $2 \mathrm{mmol} / \mathrm{l} \mathrm{L-glutamine} \mathrm{(Invitrogen;} \mathrm{Thermo}$ Fisher Scientific, Inc.), $10 \mathrm{ng} / \mathrm{ml}$ cholera toxin (Thermo Fisher Scientific, Inc.), $0.005 \mathrm{mg} / \mathrm{ml}$ insulin (Thermo Fisher Scientific, Inc.), $0.005 \mathrm{mg} / \mathrm{ml}$ transferrin (Thermo Fisher Scientific, Inc.), and $100 \mathrm{ng} / \mathrm{ml}$ hydrocortisone (Thermo Fisher Scientific, Inc.). 3G, a sulfonamide derivative, was dissolved in dimethyl sulfoxide (DMSO) and a $10 \mathrm{mM}$ stock solution was prepared and stored at $-20^{\circ} \mathrm{C}$. Control cells were treated with DMSO. In certain experiments, $\mathrm{N}$-acetylcysteine (NAC, $5 \mathrm{mM}$, Santa Cruz Biotechnology, Inc.) and the JNK inhibitor SP600125 (10 $\mu \mathrm{M}$, Santa Cruz Biotechnology, Inc.) were used.

Cell proliferation assay. Cell proliferation was evaluated using the 3-(4,5-dimethylthiazolyl-2)-2,5-diphenyltetrazolium bromide (MTT) assay (11). Briefly, the cells were cultured in 96-well plates at $37^{\circ} \mathrm{C}$ for $24 \mathrm{~h}$; they were treated with different concentrations $(2.5,5,10,15,20,30$ and $40 \mu \mathrm{M}$ of $3 \mathrm{G}$ for $24 \mathrm{~h}$. $10 \mu \mathrm{l}$ of freshly prepared MTT solution $(5 \mathrm{mM})$ was added to the cells and further incubation was performed for $2 \mathrm{~h}$ at $37^{\circ} \mathrm{C}$ in $5 \% \mathrm{CO}_{2}$. Thereafter, DMSO was added to solubilize the formazan crystals. The optical density was read at $540 \mathrm{~nm}$ using a microplate reader. The mean and standard deviation values of three independent experiments were determined. The half-maximal inhibitory concentration $\left(\mathrm{IC}_{50}\right)$ value was calculated as follows by plotting drug (3G) concentration against percent activity ([I]-Activity \% graph), using the linear $(y=m x+n)$ equation on this graph for $y=50 . T h e \mathrm{IC}_{50}$ value is indicated by the value of $x$.

Cytotoxicity assay using the xCELLigence system. Optimal seeding numbers for HT-29 and SW620 cells were determined as previously reported (12). Briefly, HT-29 (5,000 cells) and SW620 (12,000 cells) cells in $150 \mu 1 \mathrm{medium} /$ well were cultured in a 16-well E-plate (ACEA Biosciences Inc.) as instructed by the manufacturer of the xCELLigence Real-Time Cell Analyzer-DP system. After 24 h, 3G was added and incubation continued at $37^{\circ} \mathrm{C}$, cell index was recorded at $15 \mathrm{~min}$ intervals for 4 days. Baseline cell indices were determined for at least two measurements from three replicate experiments.

Evaluation of apoptosis/necrosis by flow cytometry. Apoptosis and necrosis were determined as reported previously (12). 100,000 cells were cultured at $37^{\circ} \mathrm{C}$ in 6 -well plates; the next day, they were treated with $3 \mathrm{G}(20 \mu \mathrm{M})$ at $37^{\circ} \mathrm{C}$ for $24 \mathrm{~h}$. Detection of apoptosis was performed using the Annexin V/Dead Cell Apoptosis kit (cat. no. V13242, Molecular Probes; Thermo Fisher Scientific, Inc.) following the manufacturer's instructions. Cells were resuspended in Annexin-binding buffer and incubated at $25^{\circ} \mathrm{C}$ with Annexin V-fluorescein isothiocyanate (FITC; $5 \mu \mathrm{l}$ ) and propidium iodide (PI; $1 \mu \mathrm{l}$ ) for $15 \mathrm{~min}$. Data acquisition and analysis were performed using CellQuest Pro Version 6.0 BD FACSCALIBUR (BD Biosciences) and analysis were performed, wherein fluorescence emission was measured at $530 \mathrm{~nm}$ (FL1 channel) for FITC Annexin V and >575 nm (FL3 Channel) for PI; 10,000 events were used for each test.

Detection of cell apoptosis by fluorescence microscopy. 10,000 HT-29 cells cultured in 8-well slide chambers were treated with $3 \mathrm{G}$ as aforementioned. The Apoptosis/Necrosis Detection kit (cat. no. ab176749, Abcam) and Olympus BX51 Fluorescence Microscope (Olympus Corporation) were used. Apoptosis was detected using Apopxin Green Solution, which binds to phosphatidylserine and exhibits green fluorescence $($ Excitation $/$ Emission $=490 / 525 \mathrm{~nm})$. Cells were washed using 1X PBS, incubated with the Apopoxin and 7-AAD fluorescent markers at $25^{\circ} \mathrm{C}$ for $30 \mathrm{~min}$, and then washed twice with $1 \mathrm{X}$ PBS. The cells were fixed with $2 \%$ paraformaldehyde at $25^{\circ} \mathrm{C}$ for $30 \mathrm{~min}$. The cells were washed again with $1 \mathrm{X}$ PBS prior to visualization with a fluorescence microscope (BX51, Olympus Corporation). Images were captured at x20 magnification. A DAPI filter (UV-MNU2 Olympus) was used to analyze for DAPI staining at $25^{\circ} \mathrm{C}$ for $30 \mathrm{~min}$

Western blotting. 3G-treated cells and control cells were harvested and total lysates were prepared using radioimmunoprecipitation assay lysis buffer (Boston BioProducts) as previously described (13). Briefly, harvested cell pellets were dissolved in cell lysis buffer (Boston BioProducts), incubated on ice for $15 \mathrm{~min}$, and centrifuged at $10,000 \mathrm{x} \mathrm{g}$ 
at $4^{\circ} \mathrm{C}$ for $15 \mathrm{~min}$. Supernatant containing soluble proteins was collected and protein concentrations were determined using the Bradford protein reagent (Bio-Rad Laboratories Inc.). Equal amounts $(20 \mu \mathrm{g})$ of proteins were electrophoresed on 4-20\% Mini-Protean TGX precast gels (cat. no. 456-1094; Bio-Rad Laboratories Inc.). Proteins were transferred to nitrocellulose trans-blot turbo membranes $(0.2 \mu \mathrm{m})$ via the trans-blot turbo transfer system (Bio-Rad Laboratories Inc.). The membranes were blocked with $5 \%$ blotting-grade blocker in PBS containing $0.1 \%$ Tween-20 (PBST) for $1 \mathrm{~h}$ at $25^{\circ} \mathrm{C}$. The membranes were exposed overnight to the following primary antibodies at $4^{\circ} \mathrm{C}$ : Anti-cytochrome $c(1: 200$; Abcam, ab65311), anti-p53 (Santa Cruz Biotechnology Inc., sc-99), anti-Bcl-2-associated X protein (Bax; Santa Cruz Biotechnology Inc., sc-70408), anti-Bcl2 (Santa Cruz Biotechnology Inc., sc-492), anti-Bcl-extra large (Bcl-xL; Santa Cruz Biotechnology Inc., sc-56021), anti-cyclin D1 (Santa Cruz Biotechnology Inc., sc-8396), anti-survivin (Santa Cruz Biotechnology Inc., sc-101433), anti-X-linked inhibitor of apoptosis protein (XIAP; Santa Cruz Biotechnology Inc., sc-58537), anti-poly(ADP-ribose)polymerase (PARP, cleaved; Biovision, cat. no. 3140-100), anti-cyclin E1 (Santa Cruz Biotechnology Inc., sc-248), anti-p21 (Santa Cruz Biotechnology Inc., sc-397), and anti- $\beta$-actin (1:10,000; Santa Cruz Biotechnology Inc., sc-47778), anti-phosphorylated (P)-JNK (cat. no. 9251, Cell Signaling Technology, Inc.), anti-P-cJun (cat. no. 3270, Cell Signaling Technology, Inc.), and P-activating transcription factor 2 (ATF2; cat. no. 24329, Cell Signaling Technology, Inc.), anti-JNK (Santa Cruz Biotechnology Inc., sc-7345), anti-c-Jun (Santa Cruz Biotechnology Inc., sc-74543) and anti-ATF2 (Santa Cruz Biotechnology Inc., sc-242) antibodies. The membranes were washed with twice with PBST and once with PBS and incubated with HRP-conjugated mouse (sc-516102) and HRP-conjugated rabbit (sc-2357) secondary antibodies (1:3,000; Santa Cruz Biotechnology Inc.) at room temperature for $1 \mathrm{~h}$. Reactivity was detected by chemiluminescence by using the Clarity Western ECL substrate (Bio-Rad Laboratories Inc.). Chemiluminescence was detected using a blot scanner (LI-COR) and densitometry analysis was done using Image Studio Digits Ver 3.1 (LI-COR Biosciences).

Cytochrome c measurement. Cytosolic extracts were prepared from control and 3G-treated cells by using cytosolic extraction buffer (Invitrogen Thermo Fisher Scientific, Inc.) and centrifugation at $10,000 \mathrm{x} \mathrm{g}$ at $4^{\circ} \mathrm{C}$ for $10 \mathrm{~min}$. Subsequently, the cytosolic extracts were immunoblotted for cytochrome $c$ as aforementioned.

ROS measurement by flow cytometry. Cells were cultured to $60-70 \%$ confluency and treated with $3 \mathrm{G}$ for $24 \mathrm{~h}$. Thereafter, they were harvested by trypsinization. All cells were incubated with $1.0 \mu \mathrm{M} 2^{\prime}, 7^{\prime}$-dichlorodihydrofluorescein diacetate (DCF-DA) for $15 \mathrm{~min}$ at $37^{\circ} \mathrm{C}$. They were then washed twice with PBS and analyzed with a flow cytometer (BD FACSCalibur; CellQuest Pro Version 6.0, BD Biosciences) for ROS detection using a $488 \mathrm{~nm}$ laser for excitation and detected at $535 \mathrm{~nm}$ (FL1 channel).

Caspase-3 and caspase-7 detection by flow cytometry. The HT29 cell line was cultured and treated with $3 \mathrm{G}$ for $24 \mathrm{~h}$.
To measure the activation of the caspase cascade, we used the Vybrant ${ }^{\mathrm{TM}}$ FAM Caspase-3 and Caspase-7 assay kit (Invitrogen; Thermo Fisher Scientific, Inc.). Briefly, the cells were stained with FLICA reagent and incubated for $60 \mathrm{~min}$ at $37^{\circ} \mathrm{C}$ under $5 \% \mathrm{CO}_{2}$. Then, the cells were washed twice with washing buffer followed by the addition of PI and incubation for 5-10 min at room temperature. The stained cells were analyzed using BD FACSCalibur (CellQuest Pro Version 6.0) with excitation at $488 \mathrm{~nm}$ and green emission for the FLICA-stained cells (FL1) or red emission for PI (FL3).

Statistical analysis. All the experiments were performed in triplicate and the results were expressed as mean of three independent experiments (mean \pm standard deviation). Statistical analyses were performed using GraphPad Prism 7 (GraphPad Software Inc,). The mean values between the control and treated groups were compared using a two-tailed Student's t-test and one-way analysis of variance followed by a Tukey's post hoc test. $\mathrm{P} \leq 0.05$ was considered to indicate a statistically significant difference.

\section{Results}

$3 G$ inhibits cell proliferation. To determine the cytotoxic activity of 3G (Fig. 1A), the human adenoma CRC cell line HT-29 was treated with different concentrations of $3 \mathrm{G}$. As expected, 3G inhibited the viability of HT-29 cells in a dose-dependent manner (Fig. 1B). A similar finding was observed in the metastatic CRC cell line SW620 (Fig. 1C). $3 \mathrm{G}$ treatment of normal colon epithelial cells, FHC, resulted in little inhibition of cell viability (Fig. 1D). To confirm these findings, we employed another technique, real-time measurement of cell proliferation by using the xCelligence RTDP machine. To this end, HT-29 cells were cultured in an E-plate for $24 \mathrm{~h}$ and then treated with different concentrations of $3 \mathrm{G}$. We found that $3 \mathrm{G}$ inhibited cell viability in a time- and dose-dependent manner (Fig. 2A). Similarly, 3G also inhibited the viability of the metastatic CRC cell line SW620 in a dose-dependent manner as compared with the control (Fig. 2B). Both the techniques work on different principles. MTT is an end point method; however, xCelligence RTDP analysis determines cell proliferation by measuring the cellular impedance in real time. Both the methodologies were found to indicate a similar trend of inhibited cell proliferation by $3 \mathrm{G}$. These findings demonstrated that $3 \mathrm{G}$ effectively inhibited the viability of different CRC cell lines with no or little effect on normal cells.

$3 G$ modulates p53, Bcl2, and IAP family protein expression. $\mathrm{P} 53$ is a well-known tumor suppressor gene controlling cellular homeostasis (14). HT-29 cells treated with 3G demonstrated upregulated p53 expression (Fig. 3A). Treatment of the metastatic CRC cell line SW620 with 3G also resulted in increased p53 expression (Fig. 3B). The $\mathrm{Bcl} 2$ family of proteins is known to regulate cell proliferation and apoptosis. The balance between proapoptotic and antiapoptotic protein expression determines cell fate under stress (15). The treatment of HT-29 cells with different concentrations of $3 \mathrm{G}$ resulted in the elevated expression of Bax, and inhibition of $\mathrm{Bcl} 2$ and $\mathrm{Bcl}-\mathrm{xL}$ (Fig. 3A). A similar result was obtained in SW620 cells (Fig. 3B). The 
A Structure of $3 G$

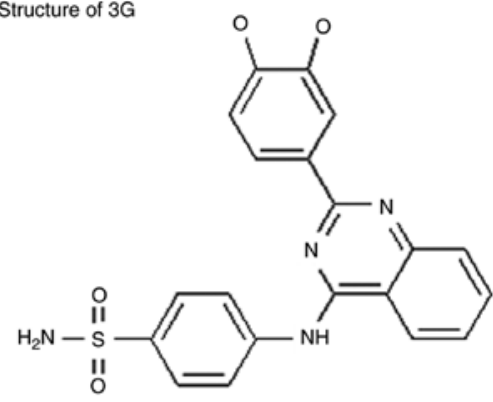

4-((2-(Benzo[d] $[1,3]$ dioxol-5-y))quinazolin-4yl)amino)benzenesulfonamide

C

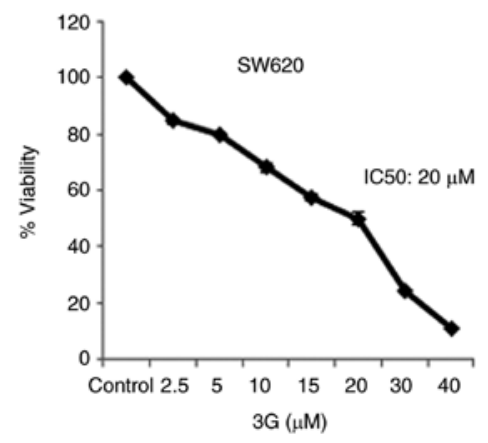

B

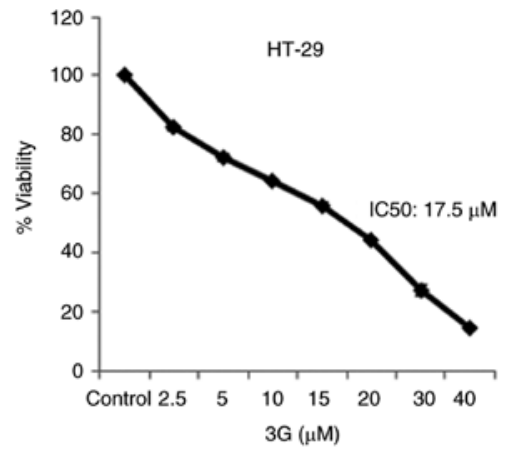

D

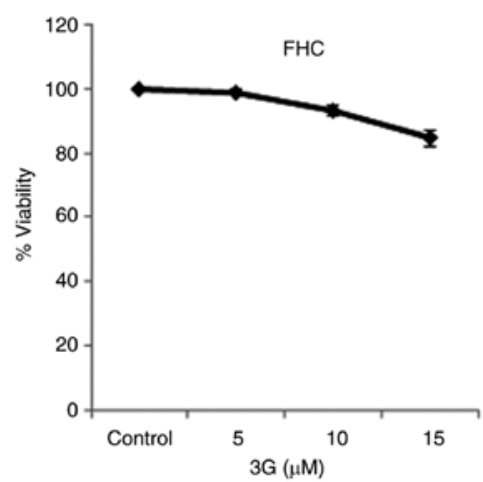

Figure 1.3G inhibits cell proliferation. (A) Structure of 3G. (B and C) HT-29 and SW620 cells were treated with different concentrations of 3G as indicated. Cell proliferation was measured by the MTT assay. (D) The normal colon epithelial cell line, FHC, was treated with different concentrations of $3 \mathrm{G}$ for $24 \mathrm{~h}$. Cell proliferation was determined using the MTT assay and the results were expressed the mean \pm standard deviation of three experiments.

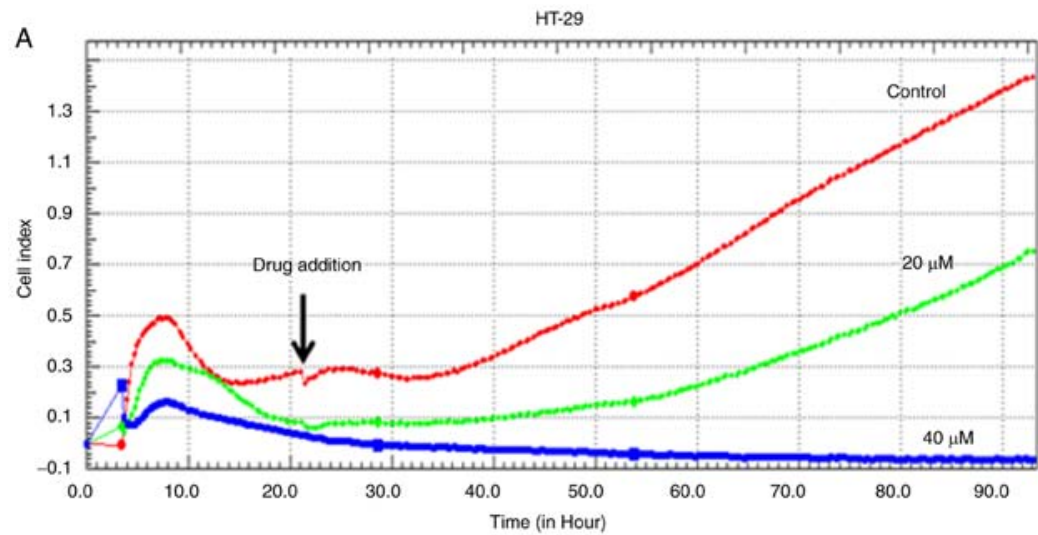

B

SW620

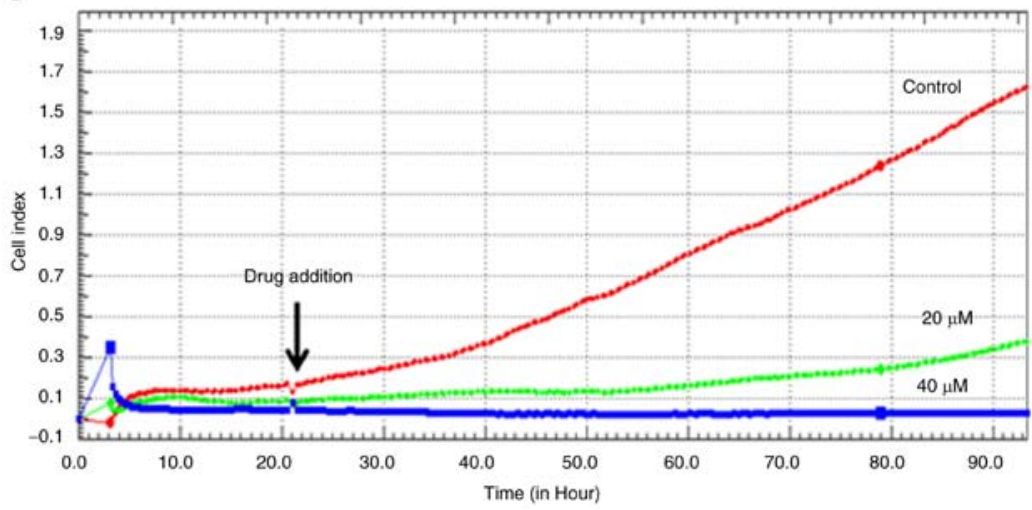

Figure 2. 3G inhibits real-time cell proliferation. (A) 5,000 HT-29 cells were seeded in a 16-well E-plate for $24 \mathrm{~h}$. The next day, the cells were treated with different concentrations of 3G. Real-time cell proliferation of HT-29 cells was evaluated by measuring cell indexes to assess the cytotoxic effect of $3 \mathrm{G}$ by using the xCELLigence RTCA-DP system. (B) SW620 cells (12,000 cells/well) were seeded in an E-plate. After $24 \mathrm{~h}$, the cells were treated with different concentrations of 3G. Real-time cell proliferation was determined by measuring cell indexes in the control and 3G-treated cells. 

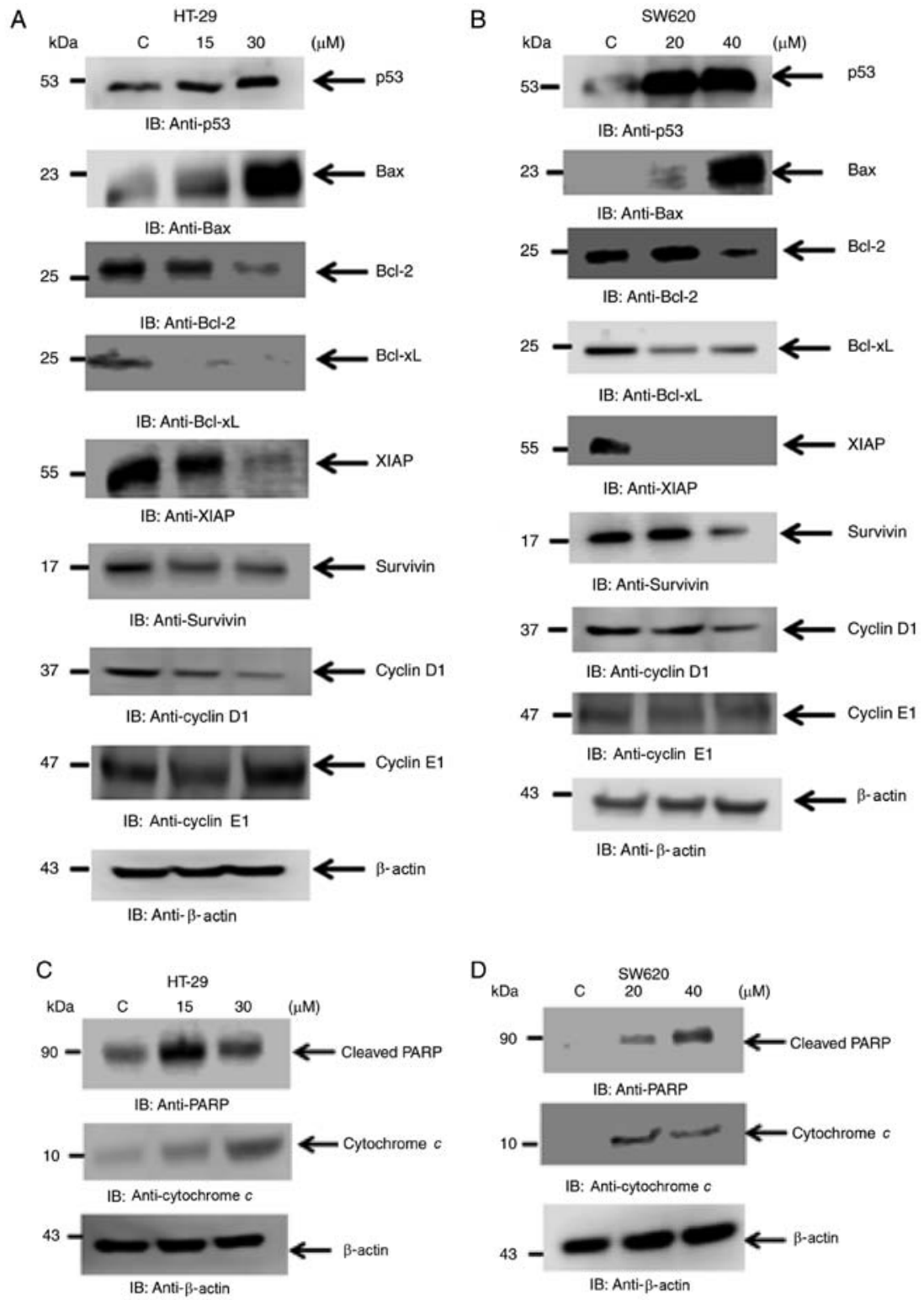

Figure 3. 3G modulates p53, Bcl2 and IAP family protein expression. (A and B) HT-29 and SW620 cells were treated with different concentrations of 3G for $24 \mathrm{~h}$. Cell lysates were immunoblotted with appropriate antibodies. (C and D) HT-29 and SW620 cells treated with 3G for 24 h. Cytosolic extracts were prepared and immunoblotted with the indicated antibodies. Bcl-xL, Bcl-2-extra large; Bax, Bcl-2-associated X protein; PARP, poly(ADP-ribose)polymerase; XIAP, X-linked inhibitor of apoptosis protein.

cell cycle serves a critical role in cellular transformation and tumor progression. Cyclins are known to regulate the cell cycle in tumorigenesis (16). 3G-treated HT-29 cells exhibited downregulated cyclin D1 expression in a dose-dependent manner (Fig. 3A). 3G treatment of SW620 cells resulted in the depletion of cyclin D1 expression without notable alterations in that of cyclin E1 (Fig. 3B). Survivin and XIAP belong to the IAP family of proteins, and are known to inhibit caspase activation, thereby negatively regulating apoptosis in the process of programmed cell death (17). 3G inhibited survivin and XIAP protein expression in HT-29 and SW620 cells (Fig. 3A and B).

$3 G$ activates PARP and cytochrome c release. During cellular stress, the ratio of proapoptotic to antiapoptotic proteins determines whether the cells undergo cell death (15). Inhibition of $\mathrm{Bcl} 2$ and Bcl-xL releases Bax, which forms oligomers, resulting in the alteration of the outer mitochondrial membrane potential and leads to the release of cytochrome $c$ into the cytosol (18). Cells undergoing stress experience PARP activation by cleavage, leading to ATP depletion and thereby cell lysis (18). In this study, 3G was found to activate PARP and induce cytochrome $c$ release in the cytosolic fraction in HT29 (Fig. 3C) and SW620 cells (Fig. 3D).

$3 G$ induces apoptosis and necrosis. We investigated whether 3G could induce cell death in CRC cell lines. To this end, HT-29 cells were treated with $3 \mathrm{G}$ for $24 \mathrm{~h}$ and then stained with Annexin V and PI. 3G treatment for $24 \mathrm{~h}$ increased the percentage of cell death, from $5.9 \%$ in the control to $38 \%$, which comprised apoptotic (12.4\%) and necrotic cells (25.6\%; Fig. 4A). These findings were confirmed by staining $3 \mathrm{G}$-treated cells with apopxin and 7-ADD by using immunofluorescence. 3G-treated HT-29 cells stained positive with apopxin and 7-ADD, indicating cell death (Fig. 4B). 3G treatment of SW620 
A
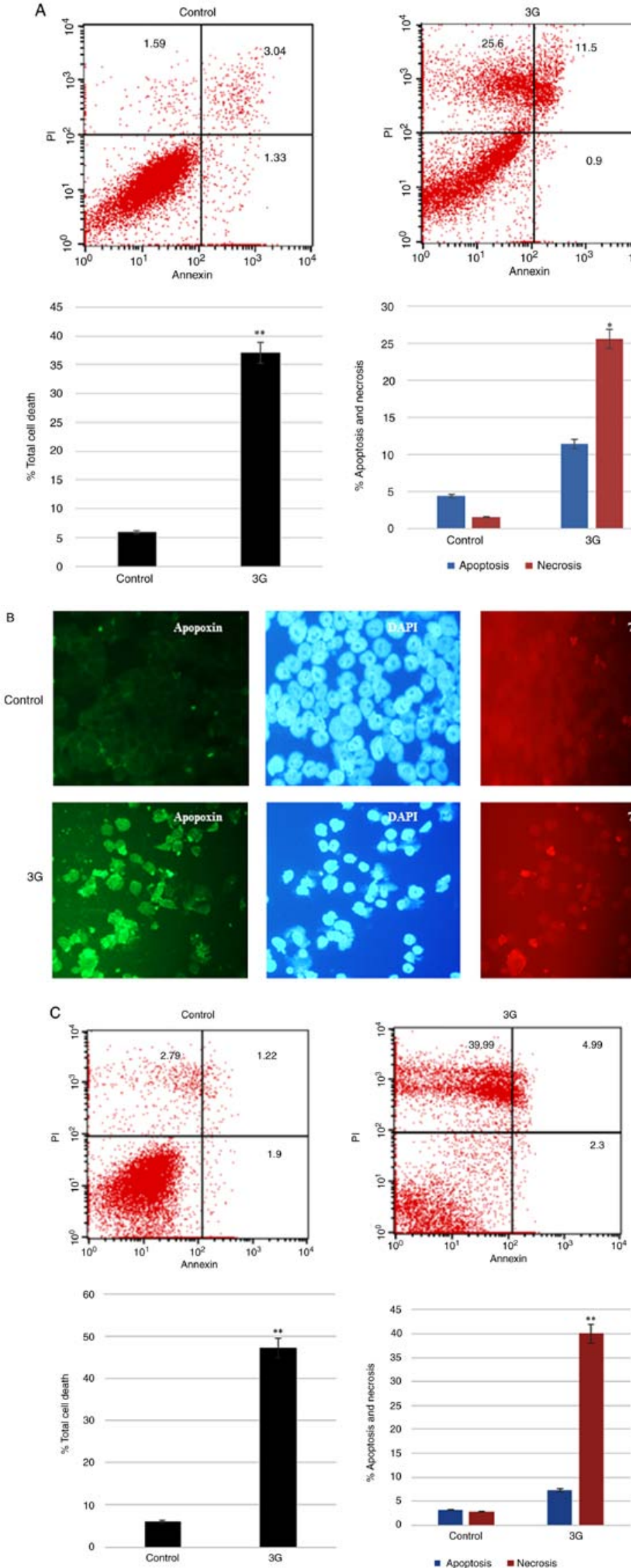

Figure 4.3G induces apoptosis and necrosis. (A) HT-29 cells were treated with $3 \mathrm{G}(20 \mu \mathrm{M})$ for $24 \mathrm{~h}$. Total cell death, including apoptosis and necrosis, was measured by Annexin V/PI staining by using flow cytometry. Results shown are representative of three independent experiments. ${ }^{*} \mathrm{P}<0.05{ }^{* * *} \mathrm{P}<0.01$ vs. control; $(\mathrm{B}) \mathrm{HT}-29$ cells were treated with $3 \mathrm{G}$ for $24 \mathrm{~h}$, and then incubated with the green Apopxin solution and 7-ADD and green fluorescence (Excitation/Emission=490/525 nm) was measured by fluorescence microscopy vs. the 7AAD and DAPI stains (for whole cell content visualization). Magnification, x20. (C) SW620 cells were treated with $3 \mathrm{G}$ for $24 \mathrm{~h}$. Total cell death comprising apoptosis and necrosis was measured using Annexin V/PI staining by flow cytometry. The results shown are representative of three independent experiments. ${ }^{* *} \mathrm{P}<0.01 \mathrm{vs}$. control. 

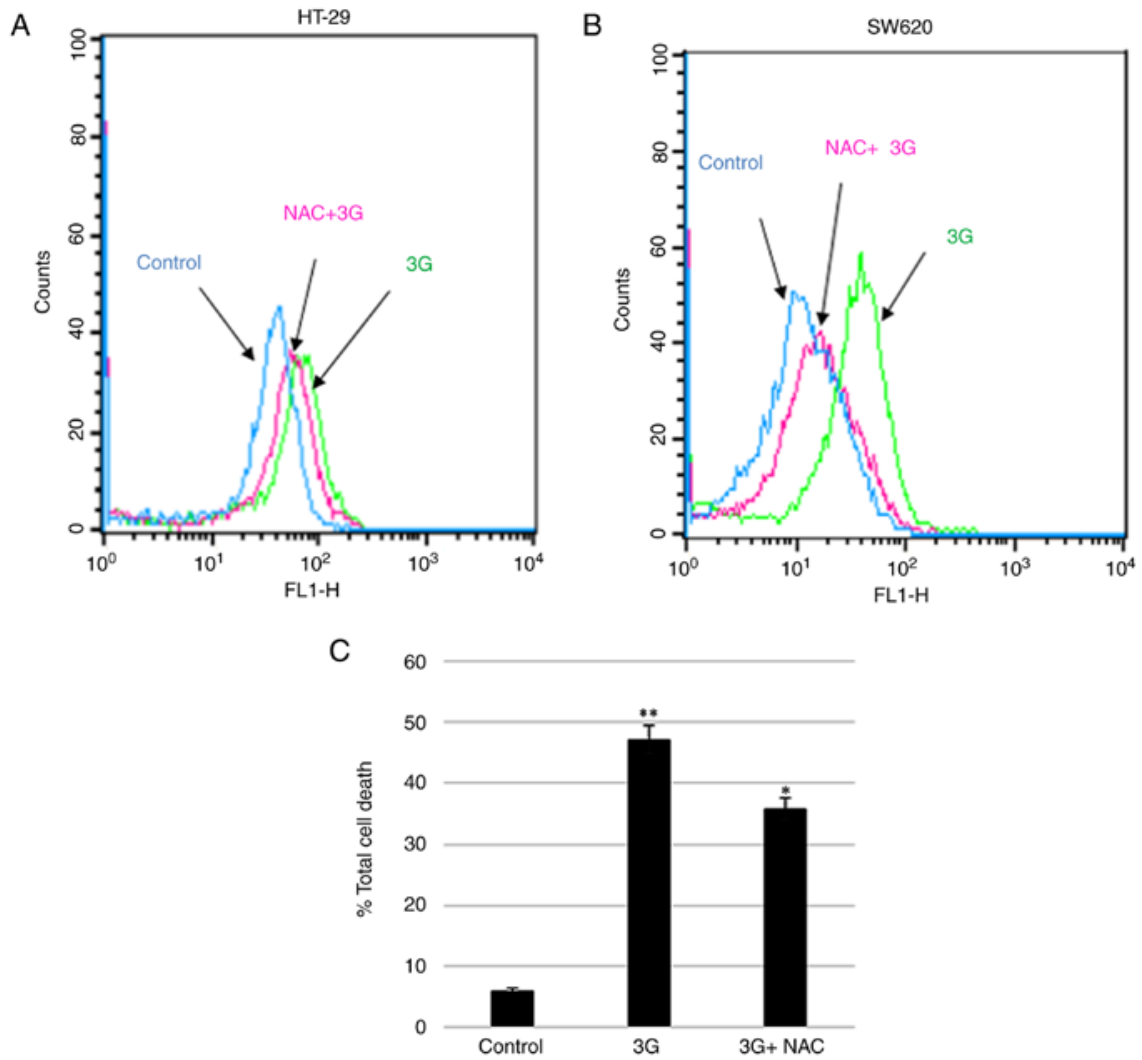

Figure 5. 3G induces reactive oxygen species-mediated cell death. (A and B) HT29 and SW620 cells were treated with 3G (20 $\mu$ M) for 24 h. Cells were incubated with 2',7'-dichlorodihydrofluorescein diacetate for $15 \mathrm{~min}$, and the fluorescence of the oxidized 2',7'-dichlorofluorescein was measured using flow cytometry. (C) SW620 cells were pretreated with NAC (5 mM) for $1 \mathrm{~h}$ and then treated with $3 \mathrm{G}(20 \mu \mathrm{M})$ for $24 \mathrm{~h}$. Total cell death comprising apoptosis and necrosis was measured using Annexin V/propidium iodide staining by flow cytometry. The results shown are representative of three independent experiments. NAC, $\mathrm{N}$-acetyl cysteine. ${ }^{*} \mathrm{P}<0.05$ vs. $3 \mathrm{G} ;{ }^{* *} \mathrm{P}<0.01$ vs. control.

cells resulted in $7.3 \%$ apoptosis as compared with $3.1 \%$ in control cells. Additionally, 3G-treated SW620 cells exhibited a significant increase in necrosis to $39.99 \%$ compared with only $2.79 \%$ in the control cells (Fig. 4C). Thus, these findings indicate that $3 \mathrm{G}$ induced cell death via both apoptosis and necrosis.

$3 G$ induces ROS-mediated cell death. To determine whether $3 \mathrm{G}$ has any effect on ROS production in CRC cell lines and whether the induction of $3 \mathrm{G}$-induced cell death is mediated by ROS, we used a fluorescent probe (DCF-DA) to monitor the intracellular ROS generation in control and 3G-treated cells. As shown in Fig. 5A, 3G-treated cells demonstrated notably higher ROS production than control cells as indicated by a right shift of the peak. NAC is a common antioxidant; pretreatment with NAC resulted in a decrease in ROS levels (Fig. 5A). Similarly, 3G-treated SW620 cells exhibited elevated ROS levels; however, pretreatment with NAC resulted in suppressed ROS generation (Fig. 5B). To determine whether $3 \mathrm{G}$-induced cell death is mediated by ROS production, we evaluated $3 \mathrm{G}$-induced apoptosis in cells pretreated with NAC, a ROS scavenger. SW620 cells were pretreated with or without NAC $(5 \mathrm{mM})$ for $1 \mathrm{~h}$, and were then subjected to $3 \mathrm{G}$ treatment for $24 \mathrm{~h}$. As expected, pretreatment of cells with NAC induced a significant decrease in ROS-mediated apoptosis when compared $3 \mathrm{G}$ treatment alone (Fig. 5C). These data suggest that 3G-induced apoptosis and necrosis in CRC cells may be mediated by elevated ROS production.

$3 G$ activates the JNK pathway. Several anticancer agents induce ROS generation and activate the MAPK signaling pathway, resulting in the induction of cell death $(19,20)$. In the present study, we determined the JNK phosphorylation status. HT-29 cells treated with different concentrations of $3 \mathrm{G}$ exhibited increased phosphorylation of JNK, and downstream target substrates cJun and ATF2, indicating that $3 \mathrm{G}$ activated this pathway (Fig. 6A-C). The activation of JNK in SW620 cells exposed to $3 \mathrm{G}$ for $24 \mathrm{~h}$ was evaluated by immunoblotting. The phosphorylation of JNK increased after $3 \mathrm{G}$ treatment. To confirm the activation of the JNK pathway, its downstream effectors were evaluated. SW620 cells treated with $3 \mathrm{G}$ exhibited increased phosphorylation of downstream target substrates of the JNK pathway, such as cJun and ATF2 (Fig. 6B-D). We used the JNK inhibitor SP600125 to confirm our findings. HT-29 cells were pretreated with SP600125 and then $3 \mathrm{G}$ for $24 \mathrm{~h}$, after which caspase-3/7 activation was measured. The JNK inhibitor alleviated the $3 \mathrm{G}$-induced caspase-3/7 activation, confirming that $3 \mathrm{G}$-induced cell death is likely to be mediated by JNK activation (Fig. 7A). Similarly, it inhibited the 3G-induced PARP cleavage and cytochrome $c$ release (Fig. 7B-E). These findings thus demonstrate that $3 \mathrm{G}$-induced cell death may be mediated by ROS generation and JNK pathway activation. 
A

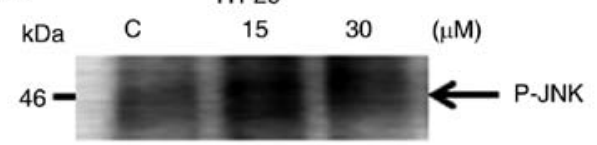

IB: Anti-P-JNK

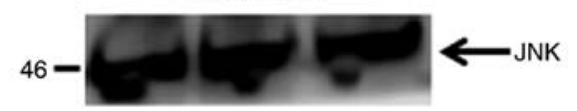

IB: Anti-JNK

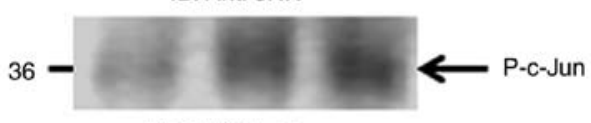

IB: Anti-P-C-Jun

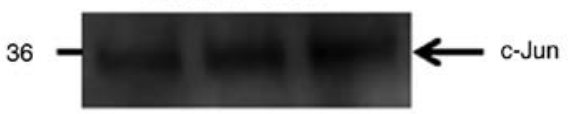

IB: Anti-c-Jun

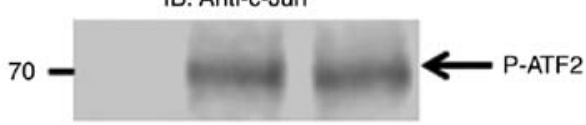

IB: Anti-P-ATF2

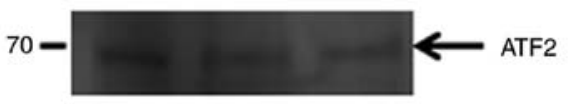

IB: Anti-ATF2

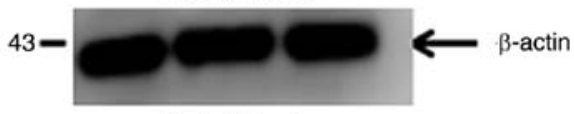

IB: Anti- $\beta$-actin

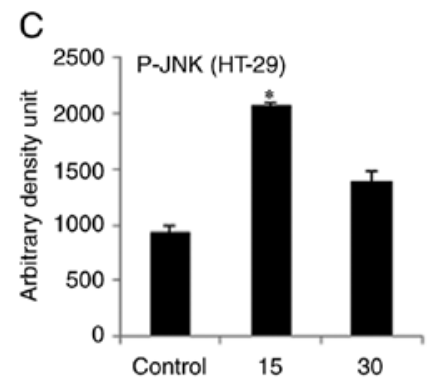

D

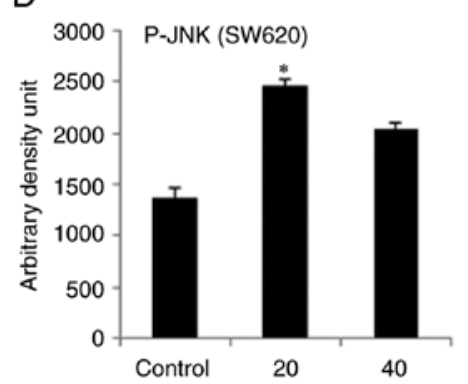

B

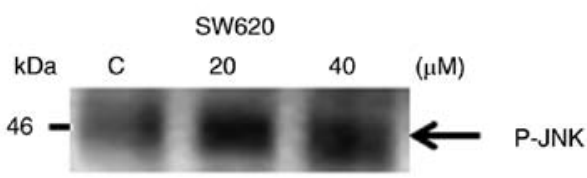

IB: Anti-P-JNK

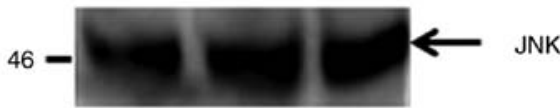

IB: Anti-JNK

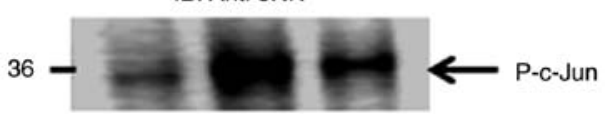

IB: Anti-P-C-Jun

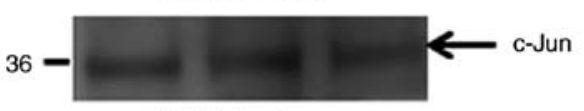

IB: Anti-c-Jun

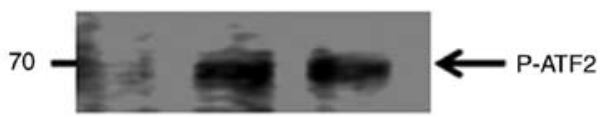

IB: Anti-P-ATF2

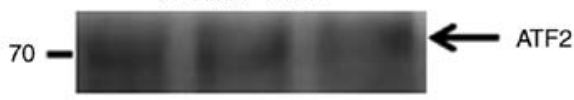

IB: Anti-ATF2

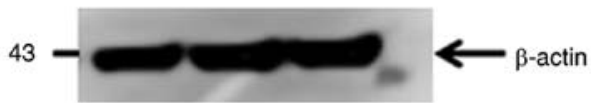

IB: Anti- $\beta$-actin
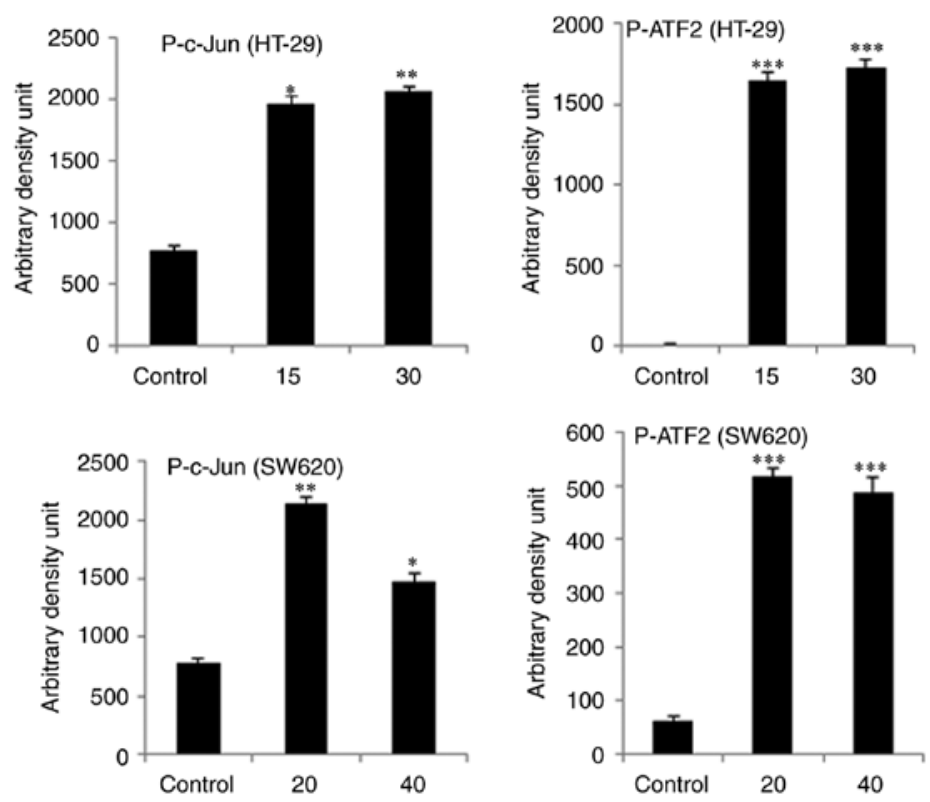

Figure 6. 3G activates the JNK signaling pathway. (A and B) HT-29 and SW620 were treated with different concentrations of $3 \mathrm{G}$ for $24 \mathrm{~h}$. Cell lysates were immunoblotted with the indicated antibodies. (C and D) Densitometry of the individual band was performed and analyzed. ${ }^{*} \mathrm{P}<0.05,{ }^{* *} \mathrm{P}<0.01,{ }^{* * * *} \mathrm{P}<0.001$ vs. control. ATF2, activating transcription factor 2; p, phosphorylated.

\section{Discussion}

Sulfonamide and several of its derivatives have been reported to have potential as anticancer agents for application in the treatment of various cancers. Liu et al (21) showed that para-toluenesulfonamide induced cell death in tongue squamous cell cancer. Saha et al (22) revealed the apoptosis-inducing activity of bis(sulfonamide) in HeLa cells. The trans-sulfonamide-platinum complex was reported to induce anti-tumor activity against melanoma cancer cell lines (23). Our previous findings have shown that certain novel derivatives of sulfonamide possess anticancer activity (11-13). In the present study, we evaluated the antiproliferative effects of $3 \mathrm{G}$ in human CRC cell lines. 


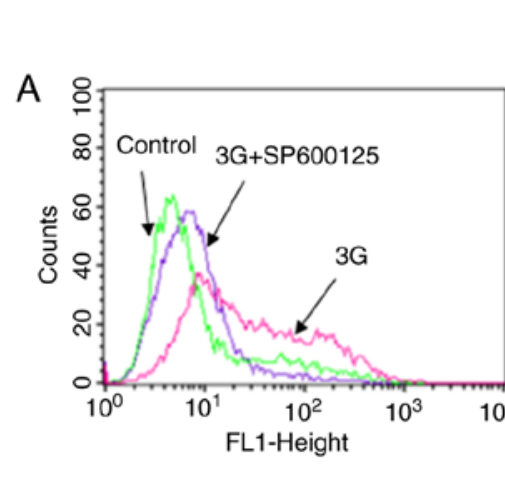

B

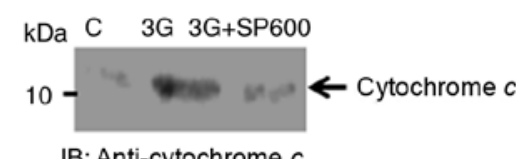

IB: Anti-cytochrome c
C

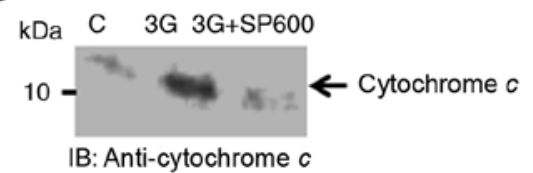

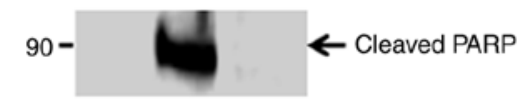

IB: Anti-PARP

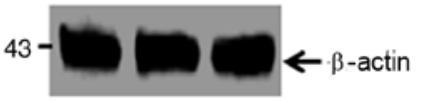

IB: Anti- $\beta$-actin

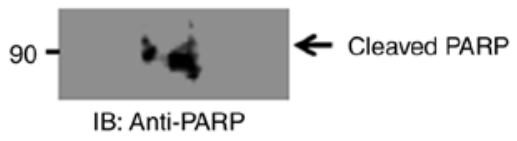

43

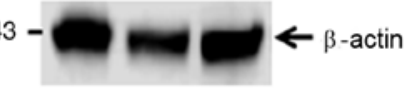

IB: Anti- $\beta$-actin
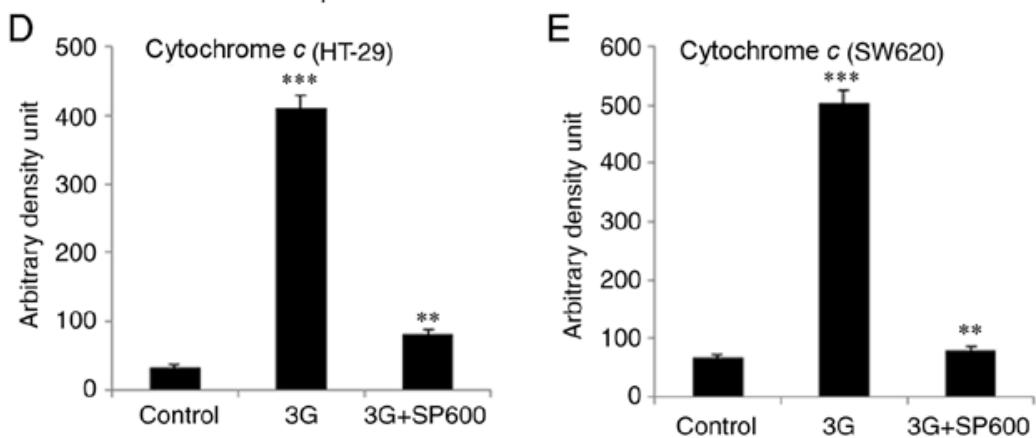

Figure 7. JNK inhibitor blocks the effects of 3G. (A) HT-29 cells were pretreated with a JNK inhibitor (SP600125, $10 \mu \mathrm{M}$ ) and then treated with 3G $(20 \mu \mathrm{M})$ for $24 \mathrm{~h}$. Activation of caspase-3 and caspase-7 was analyzed using flow cytometry. (B and C) HT-29 and SW620 cells were pretreated with the JNK inhibitor SP600125 $(10 \mu \mathrm{M})$ for $1 \mathrm{~h}$ and then exposed to 3G $(20 \mu \mathrm{M})$ for $24 \mathrm{~h}$. Cytosolic extracts were prepared and immunoblotted with appropriate antibodies. (D and E) Densitometry of the individual bands was performed and analyzed. ${ }^{* *} \mathrm{P}<0.01$ vs. $3 \mathrm{G} ;{ }^{* * *} \mathrm{P}<0.001$ vs. control.

$3 \mathrm{G}$ exhibited cytotoxicity in a dose- and time-dependent manner in adenocarcinoma (HT-29) and metastatic CRC cells (SW620). Cellular transformation in these cell lines occurs with a mutation in the tumor suppressor gene and activation of tumor initiation (24).

p53 is a well-known tumor suppressor gene; it undergoes mutation, thereby initiating uncontrolled cell proliferation. $3 \mathrm{G}$ treatment resulted in a dose-dependent increase in $\mathrm{p} 53$ protein expression in the present study. The $\mathrm{Bcl} 2$ family of proteins constitutes proapoptotic (Bax, Bad and Bak) and antiapoptotic ( $\mathrm{Bcl} 2, \mathrm{Bcl}-\mathrm{xL}$, and myeloid leukemia cell differentiation protein 1) proteins, which controls cell death under conditions of stress (15). Bcl2 and Bcl-xL expression inhibits apoptosis and promotes cell survival (25). Aberrant expression of $\mathrm{Bcl} 2$ is indicative of an early event in colorectal carcinogenesis that can block apoptosis (26). The antiapoptotic protein Bcl-xL has been identified as a driver of colorectal carcinogenesis, thus making it a target for cancer therapeutics (27). In this study, we found that $3 \mathrm{G}$ inhibited $\mathrm{Bcl} 2$ and $\mathrm{Bcl}-\mathrm{xL}$ protein expression in human CRC cell lines. Therefore, the induction of $\mathrm{p} 53$, and depletion of $\mathrm{Bcl} 2$ and $\mathrm{Bcl}-\mathrm{xL}$ protein expression suggest a mechanism of action for 3G-mediated inhibition of cell proliferation. Cyclin D1 serves an important role in cellular proliferation and its aberrant regulation has been linked to colorectal tumorigenesis (28). The sulfonamide derivative $3 \mathrm{G}$ inhibited cyclin D1 expression in HT-29 and SW620 cells. XIAP and survivin belong to the IAP family of proteins, which have been shown to be significantly correlated with colorectal tumorigenesis $(29,30)$. Importantly, 3G inhibited XIAP and survivin protein expression in CRC cells.
We reported that $3 \mathrm{G}$ could trigger a significant increase in apoptosis and necrosis in CRC cells. Importantly, ROS levels in HT-29 and SW620 cells were significantly elevated by $3 \mathrm{G}$ treatment. Previous reports have suggested that some small-molecule and natural products possess pro-oxidant properties (31-33). We have determined that certain derivatives of sulfonamide induce ROS production $(12,13)$. Treating cells with natural products, such as curcumin and resveratrol, resulted in pro-oxidant and antioxidant effects, depending on the concentrations of the compounds used $(34,35)$. The antioxidant NAC could significantly attenuate $3 \mathrm{G}$-induced apoptosis in CRC cells in our study. Generally, tumor cells have higher levels of ROS and cannot tolerate further ROS insults (36). MAPK-like JNK and p38 kinase are known as stress-activated protein kinases (37). Certain studies have previously reported that p38 MAPK and JNK activation plays a critical role in sulfonamide derivative-induced cellular apoptosis $(38,39)$. Consistent with this finding, another sulfonamide derivative has shown similar effects on CRC cells (40). Furthermore, we reported that $3 \mathrm{G}$ induced a significant increase in the phosphorylation of JNK in a dose-dependent manner. In addition, 3G-induced activation of JNK further phosphorylated its downstream target substrates, including cJun and ATF2. These findings demonstrated that $3 \mathrm{G}$ indeed activates the JNK pathway in CRC cells. Therefore, the mutual augmentation of JNK activation and ROS production in 3G-induced cell death may be key in the mechanism underlying the effects of $3 \mathrm{G}$. In summary, our results suggested that $3 \mathrm{G}$ could efficiently induce ROS-mediated cell death in human CRC cells. The cytotoxic effects of $3 \mathrm{G}$ could be mediated by the induction of 
ROS generation and activation of the JNK pathway. Therefore, our findings indicate that $3 \mathrm{G}$ may have potential as an antitumor agent for the treatment of CRC. Further investigation is required to determine its effects in animal models and in combination therapy.

\section{Acknowledgements}

The authors are grateful to the Deanship of Scientific Research, King Saud University, for funding through the Vice Deanship of Scientific Research Chairs. The authors thank the Investigator support unit at King Saud University for technical support.

\section{Funding}

The authors are grateful to the Deanship of Scientific Research, King Saud University, for funding through the Vice Deanship of Scientific Research Chairs.

\section{Availability of data and materials}

All data generated are included in this research paper.

\section{Authors' contributions}

Conception and design of experiments: RA, MAVM, and ME; acquisition of data: MAVM, ME, and WME; analysis and interpretation of data: RA, OAO, KAK, AA, and HAA; drafting of manuscript: RA, MA, AA, HAAA, and WME; critical reading and revision: RA, MAVM, ME, AA, and MA. All authors read and approved the final manuscript.

\section{Ethics approval and consent to participate}

Not applicable.

\section{Patient consent for publication}

Not applicable.

\section{Competing interest}

All authors declare that they have no competing interest related to this work.

\section{References}

1. American Cancer Society. Cancer Facts \& Figures 2018. Atlanta GA: American Cancer Society; 2018. https://www.cancer.org/ research/cancer-facts-statistics/all-cancer-facts-figures/cancer-factsfigures-2018.html. Accessed November 22, 2018.

2. Zubaidi AM, AlSubaie NM, AlHumaid AA, Shaik SA AlKhayal KA and AlObeed OA: Public awareness of colorectal cancer in Saudi Arabia: A survey of 1070 participants in Riyadh. Saudi J Gastroenterol 21: 78-83, 2015.

3. Kuipers EJ, Grady WM, Lieberman D, Seufferlein T, Sung JJ, Boelens PG, van de Velde CJ and Watanabe T: Colorectal cancer. Nat Rev Dis Primers 1: 15065, 2015.

4. Sreevalsan S and Safe S: Reactive oxygen species and colorectal cancer. Curr Colorectal Cancer Rep 9: 350-357, 2013.

5. Trachootham D, Alexandre J and Huang P: Targeting cancer cells by ROS-mediated mechanisms: A radical therapeutic approach? Nat Rev Drug Discov 8: 579-591, 2009.
6. Larocque K, Ovadje P, Djurdjevic S, Mehdi M, Green J and Pandey S: Novel analogue of colchicine induces selective pro-death autophagy and necrosis in human cancer cells. PLoS One 9: e87064, 2014.

7. Kim AD, Kang KA, Kim HS, Kim DH, Choi YH, Lee SJ, Kim HS and Hyun JW: A ginseng metabolite, compound K, induces autophagy and apoptosis via generation of reactive oxygen species and activation of JNK in human colon cancer cells. Cell Death Dis 4: e750, 2013.

8. Kim JY, Yu SJ, Oh HJ, Lee JY, Kim Y and Sohn J: Panaxydol induces apoptosis through an increased intracellular calcium level, activation of JNK and p38 MAPK and NADPH oxidase-dependent generation of reactive oxygen species. Apoptosis 16: 347-358, 2011.

9. Ramiro-Cortés Y, Guemez-Gamboa A and Morán J: Reactive oxygen species participate in the $\mathrm{p} 38$-mediated apoptosis induced by potassium deprivation and staurosporine in cerebellar granule neurons. Int J Biochem Cell Biol 43: 1373-1382, 2011.

10. Hsieh CJ, Kuo PL, Hsu YC, Huang YF, Tsai EM and Hsu YL: Arctigenin, a dietary phytoestrogen, induces apoptosis of estrogen receptor-negative breast cancer cells through the ROS/p38 MAPK pathway and epigenetic regulation. Free Radic Biol Med 67: 159-170, 2014.

11. Alafeefy AM, Ahmad R, Abdulla M, Eldehna WM, Al-Tamimi AM, Abdel-Aziz HA, Al-Obaid O, Carta F, Al-Kahtani AA and Supuran CT: Development of certain new 2-substituted-quinazolin-4-yl-aminobenzenesulfonamide as potential antitumor agents. Eur J Med Chem 109: 247-253, 2016.

12. Al-Khayal K, Alafeefy A, Vaali-Mohammed MA, Mahmood A, Zubaidi A, Al-Obeed O, Khan Z, Abdulla M and Ahmad R: Novel derivative of aminobenzenesulfonamide (3c) induces apoptosis in colorectal cancer cells through ROS generation and inhibits cell migration. BMC Cancer 17: 4, 2017.

13. Al-Obeed O, Vaali-Mohammed MA, Eldehna WM, Al-Khayal K, Mahmood A, Abdel-Aziz HA, Zubaidi A, Alafeefy A, Abdulla M and Ahmad R: Novel quinazoline-based sulfonamide derivative (3D) induces apoptosis in colorectal cancer by inhibiting JAK2-STAT3 pathway. Onco Targets Ther 11: 3313-3322, 2018.

14. Olovnikov IA, Kravchenko JE and Chumakov PM: Homeostatic function of the p53 tumor suppressor: Regulation of energy metabolism and antioxidant defence. Semin Cancer Biol 19: 32-41, 2009.

15. Shamas-Din A, Kale J, Leber B and Andrews DW: Mechanism of action of Bcl-2 family proteins. Cold Spring Harb Perspect Biol 5: a008714, 2013.

16. Casimiro MC, Crosariol M, Loro E, Li Z and Pestell RG: Cyclins and cell cycle control in cancer and disease. Genes Cancer 3: 649-657, 2012.

17. Altieri DC: Survivin and IAP proteins in cell death mechanisms. Biochem J 430: 199-205, 2010.

18. Soldani C and Scovassi AI: Poly(ADP-ribose) polymerase-1 cleavage during apoptosis: An update. Apoptosis 7: 321-328, 2002.

19. Raj L, Ide T, Gurkar AU, Foley M, Schenone M, Li X, Tolliday NJ, Golub TR, Carr SA, Shamji AF, et al: Selective killing of cancer cells by a small molecule targeting the stress response to ROS. Nature 475: 231-234, 2011.

20. Zikaki K, Aggeli IK, Gaitanaki C and Beis I: Curcumin induces the apoptotic intrinsic pathway via upregulation of reactive oxygen species and JNKs in $\mathrm{H} 9 \mathrm{c} 2$ cardiac myoblasts. Apoptosis 19: 958-974, 2014.

21. Liu Z, Liang C, Zhang Z, Pan J, Xia H, Zhong N and Li L: Para-toluenesulfonamide induces tongue squamous cell carcinoma cell death through disturbing lysosomal stability. Anticancer Drugs 26: 1026-1033, 2015.

22. Saha T, Hossain MS, Saha D, Lahiri M and Talukdar P: Chloridemediated apoptosis-inducing activity of bis(sulfonamide) anionophores. J Am Chem Soc 138: 7558-7567, 2016.

23. Agudo-López A, Prieto-García E, Alemán J, Pérez C, Díaz-García CV, Parrilla-Rubio L, Cabrera S, Navarro-Ranninger C, Cortés-Funes H, López-Martín JA and Agulló-Ortuño MT: Mechanistic added value of a trans-Sulfonamide-Platinum-Complex in human melanoma cell lines and synergism with cis-Platin. Mol Cancer 16: 45, 2017.

24. Armaghany T, Wilson JD, Chu Q and Mills G: Genetic alterations in colorectal cancer. Gastrointest Cancer Res 5: 19-27, 2012.

25. Cherbonnel-Lasserre C and Dosanjh ML: Suppression of apoptosis by overexpression of Bcl-2 or Bcl-xL promotes survival and mutagenesis after oxidative damage. Biochimie 79: 613-617, 1997. 
26. Sinicrope FA, Ruan SB, Cleary KR, Stephens LC, Lee JJ and Levin B: Bcl-2 and p53 expression during colorectal tumorigenesis. Cancer Res 55: 237-241, 1995.

27. Scherr AL, Gdynia G, Salou M, Radhakrishnan P, Duglova K, Heller A, Keim S, Kautz N, Jassowicz A, Elssner C, et al: Bcl-xL is an oncogenic driver in colorectal cancer. Cell Death Dis 7 : e2342, 2016.

28. Mermelshtein A, Gerson A, Walfisch S, Delgado B, ShechterMaor G, Delgado J, Fich A and Gheber L: Expression of D-type cyclins in colon cancer and in cell lines from colon carcinoma. $\mathrm{Br}$ J Cancer 93: 338-345, 2005.

29. Takeuchi H, Kim J, Fujimoto A, Umetani N, Mori T, Bilchik A, Turner R, Tran A, Kuo C and Hoon DS: X-Linked inhibitor of apoptosis protein expression level in colorectal cancer is regulated by hepatocyte growth factor/C-met pathway via Akt signaling. Clin Cancer Res 11: 7621-7628, 2005.

30. Kalliakmanis JG, Kouvidou Ch, Latoufis C, Kouvatseas G, Anagnostakis D, Papatheodoridis G, Koskinas J and Archimandritis A: Survivin expression in colorectal carcinomas: Correlations with clinicopathological parameters and survival. Dig Dis Sci 55: 2958-2964, 2010.

31. Arihara Y, Takada K, Kamihara Y, Hayasaka N, Nakamura H Murase K, Ikeda H, Iyama S, Sato T, Miyanishi K, et al: Small molecule CP-31398 induces reactive oxygen species-dependent apoptosis in human multiple myeloma. Oncotarget 8 : 65889-65899, 2017.

32. Adams DJ, Boskovic ZV, Theriault JR, Wang AJ, Stern AM, Wagner BK, Shamji AF and Schreiber SL: Discovery of small-molecule enhancers of reactive oxygen species that are nontoxic or cause genotype-selective cell death. ACS Chem Biol 8: 923-929, 2013.
33. Weidner C, Rousseau M, Plauth A, Wowro SJ, Fischer C, Abdel-Aziz $\mathrm{H}$ and Sauer S: Iberis amara extract induces intracellular formation of reactive oxygen species and inhibits colon cancer. PLoS One 11: e0152398, 2016.

34. Marathe SA, Dasgupta I, Gnanadhas DP and Chakravortty D: Multifaceted roles of curcumin: Two sides of a coin! Expert Opin Biol Ther 11: 1485-1499, 2011.

35. Muqbil I, Beck FW, Bao B, Sarkar FH, Mohammad RM, Hadi SM and Azmi AS: Old wine in a new bottle: The warburg effect and anticancer mechanisms of resveratrol. Curr Pharm Des 18: 1645-1654, 2012

36. Liou GY and Storz P: Reactive oxygen species in cancer. Free Radic Res 44: 479-496, 2010.

37. Cargnello M and Roux PP: Activation and function of the MAPKs and their substrates, the MAPK-activated protein kinases. Microbiol Mol Biol Rev 75: 50-83, 2011.

38. Cumaoglu A, Dayan S, Agkaya AO, Ozkul Z and Ozpozan NK: Synthesis and pro-apoptotic effects of new sulfonamide derivatives via activating p38/ERK phosphorylation in cancer cells. J Enzyme Inhib Med Chem 30: 413-419, 2015.

39. Kwon Y, Song J, Lee H, Kim EY, Lee K, Lee SK and Kim S: Design, synthesis, and biological activity of sulfonamide analogues of antofine and cryptopleurine as potent and orally active antitumor agents. J Med Chem 58: 7749-7762, 2015.

40. Tülüce Y, Ahmed BA, Koyuncu İ and Durgun M: The cytotoxic, apoptotic and oxidative effects of carbonic anhydrase IX inhibitor on colorectal cancer cells. J Bioenerg Biomembr 50: 107-116, 2018. 